\title{
Consumer Tipping: A Cross-Country Study
}

\author{
MICHAEL LYNN \\ GEORGE M. ZINKHAN \\ JUDY HARRIS*
}

\begin{abstract}
Tipping differs from most economic transactions in that consumers who tip are paying a nonobligatory amount for a service that has already been received. Academic research on this unique yet pervasive consumer behavior has focused on the determinants of individuals' tipping decisions. Little attention has been directed at macrolevel issues such as cross-country differences in tipping practices and norms. This article addresses this deficiency by presenting and testing the theory that crosscountry differences in the prevalence of tipping reflect cross-country differences in values. Results of the study generally support the theory.
\end{abstract}

$\mathrm{C}$ onsumers often give gifts of money (or tips) to workers who have performed services for them. This consumer behavior differs from most other economic transactions because most economic exchanges involve clearly specified obligations that are enforced by law. Consumers who want to obtain some good or service typically have to pay a price specified by the seller. Failure to pay this price means either that the good or service is not obtained or, if it is stolen, that legal sanctions are likely to follow. In contrast, tipping involves poorly specified obligations that are enforced by social norms and/or individual conscience. Tippers are free to pay whatever they please for services that have already been rendered. Failure to tip an amount that conforms with social norms results only in social disapproval and (perhaps) pangs of guilt. This voluntary nature of tipping makes it an unusual and interesting topic for study.

Of course, tipping is more than a curiosity; it is a pervasive consumer behavior of substantial economic importance. In the United States, consumers tip over $\$ 9$ billion annually (Pearl 1985). This money represents income for service providers such as barbers, bartenders, beauticians, bellhops, casino croupiers, chambermaids, delivery persons, newspaper carriers, porters, taxicab drivers, and waiters and waitresses (Star 1988). Thus, tipping is a vital economic activity as well as an interesting form of consumer behavior.

Tipping is also a marketing phenomenon. Businesses that permit and/or encourage tipping allow their customers to set the prices of at least a portion of the service

*Michael Lynn is assistant professor of marketing, George M. Zinkhan is professor of marketing, and Judy Harris is a doctoral student in marketing at the University of Houston, Houston, TX 77204-6283. The authors thank Kent Monroe for his encouragement and suggestions. offerings of the business. Although common in many sectors of the economy, such protipping policies are not mandatory. In fact, many businesses discourage tipping by prohibiting employees from accepting tips, by posting "no tipping" signs, and/or by instituting fixed service charges (Frumpkin 1988).

In this article, we review the social science literature on tipping and note the paucity of macrolevel work on tipping customs and norms. This deficiency in the literature is particularly important because existing research at the individual level of analysis suggests that tipping is largely norm-driven behavior. We then begin to address this deficiency by developing and testing a group of theoretically derived hypotheses about crosscountry differences in the prevalence of tipping. Finally, we comment on the independence of macro- and microlevel analyses of tipping, point out that it is this independence that necessitates the study of tipping at multiple levels of analysis, and identify several directions for future macrolevel research.

\section{LITERATURE REVIEW}

Tipping has been the subject of theorizing and research in consumer behavior, economics, sociology, and psychology. This theory and research has addressed three questions: (1) Why does tipping exist? (2) What motives underlie people's tipping behavior? (3) What are the predictors of how much people tip?

\section{Explanations for the Custom of Tipping}

Explanations for the custom of tipping take one of two forms-historical or functional. Historical explanations trace the origins of tipping back to older customs from which it supposedly evolved. Functional explanations identify potential purposes of, or reasons for, 
the custom of tipping. Both types of explanations are reviewed below.

Historical Explanations. Historical explanations for the custom of tipping are common in popular writings, and many have made their way into the academic literature (Hemenway 1984; Lynn and Latane 1984; Shamir 1984). However, the origins of tipping are not entirely clear. Some authors suggest that it originated in the Middle Ages, when journeying feudal lords would toss handfuls of coins to groups of beggars on the road in order to purchase safe passage (Schein, Jablonski, and Wohlfahrt 1984). Others claim that tipping grew out of the custom of "vails," which required visitors in Tudor England to pay their hosts' servants for the extra work their visit created (see Shamir 1984). Still others claim that tipping is much older than is suggested by either of these theories (see Hemenway 1984). Even the origin of the word tip itself is in dispute. It has been suggested that tip derives from (1) the Latin word stips, meaning "gift," (2) the Dutch word tippen, meaning "to tap" (as in tapping a coin on a table or glass to attract a server's attention), (3) the gypsy phrase "tipper me your money," meaning give me your money, and (4) the words "To Insure Promptitude" that were placed on collection boxes in eighteenth-century English coffee shops (May 1978; Schein et al. 1984). Clearly these historical explanations for the custom of tipping are less than satisfactory.

A Functional Explanation. Economists have developed a functional explanation for tipping based on a transaction-cost perspective of the firm (Bodvarsson and Gibson 1988; Jacob and Page 1980). This functional analysis begins by noting that it is costly to monitor and price the various inputs to production. Firms exist because they can monitor and price these inputs more efficiently than can consumers. Their comparative advantage in monitoring and pricing the inputs to production allows firms to earn a profit by contracting with input owners and selling the outputs of production at a price that is attractive to consumers (i.e., that is below the cost to consumers of overseeing production themselves). However, the intangible and highly customized nature of many services (see Berry 1980) makes service employees' inputs difficult and costly for firms to monitor and price (Shamir 1984; Zeithaml, Berry, and Parasuraman 1988). Customers are in a better position than are firms to evaluate and reward employees' efforts to serve them; so, in order to optimize service, firms delegate these activities to customers via the institution of tipping (Bodvarsson and Gibson 1988; Hemenway 1984; Jacob and Page 1980; Shamir 1984). In other words, economists argue that the custom of tipping exists because it is the most efficient way of providing service workers with incentives to do a good job. Unfortunately, this explanation of tipping customs has not yet been systematically tested.

\section{Motives Underlying Tipping}

Tipping is voluntary behavior. Although the decision about whether or not to leave a tip is largely determined by social norms and customs, these norms provide a fair amount of latitude regarding how much should be tipped. This voluntary aspect of tipping raises a question about what motives underlie consumers' decisions about how much to tip. This question has been addressed either explicitly or implicitly in much of the academic writing on tipping. Scholars have suggested that tipping is motivated by (1) a desire for"good service during future encounters with the server (Bodvarsson and Gibson 1988; Lynn and Grassmàn 1990), (2) a desire for social approval (Crespi 1947; Holloway 1985; Lynn and Grassman 1990), (3) a desire to compensate servers equitably for their work (Holloway 1985; Lynn and Grassman 1990; Snyder 1976), and (4) a desire for status and power (Ledger 1974; May 1978; Scott 1916; Shamir 1984). Empirical tests of these hypothesized motives are scarce and most of those tests that do exist are inconclusive (e.g., Lynn and Grassman 1990). Only the idea that consumers tip in order to reward servers has received strong support. Consistent with this hypothesized motive for tipping, research has found that consumers leave larger tips the more favorably they evaluate the service (Lynn and Grassman 1990) and that consumers reward better service with larger tips only when they attribute the quality of the service to the server's efforts (Seligman et al. 1985).

\section{Predictors of Tip Size}

Numerous studies have examined the relationships between tip size and other variables. Some of the more interesting and commonly examined predictors of tip size are identified and discussed below.

Bill Size. Bill size is the largest single predictor of dollar tip size in restaurant settings-accounting for more than 50 percent of the variance in tip size in most studies (Bodvarsson and Gibson 1991; Freeman et al. 1975; Lynn 1988; Lynn and Grassman 1990; Lynn and Latane 1984; Lynn and Mynier 1993). Consistent with social norms in the United States that call for tipping 15 to 20 percent of the bill size, restaurant patrons leave larger dollar tip amounts the larger their bills. The strength of this relationship suggests that restaurant tipping is predominantly norm-driven behavior.

Server Friendliness. Server friendliness is another fairly strong predictor of restaurant patrons' tipping behavior. Studies have typically found correlations of about 4 between bill-adjusted tip amounts and servers' verbal and nonverbal signals of friendliness. For example, restaurant patrons have been found to tip more when their servers (1) introduce themselves by name (Garrity and Degelman 1990), (2) give the customers large smiles (Tidd and Lockard 1978), (3) touch the 
customers (Crusco and Wetzel 1984; Hornik 1992; Stephen and Zweigenhaft 1986), and (4) squat down next to the table when interacting with the customers (Lynn and Mynier 1993). At least for restaurant servers, friendliness appears to pay.

Service Quality. Despite tipping's ostensible role as a reward for service, service quality is a weak predictor of restaurant tip size. Studies have found consistently positive, but small ( $r \approx .15$ ), correlations between billadjusted tip amounts and restaurant patrons' service evaluations (Bodvarsson and Gibson 1991; Crusco and Wetzel 1984; Lynn 1988, 1992; Lynn and Grassman 1990, 1992; Lynn and Latane 1984). Consumers may want to reward service workers, but this motivation appears to be a relatively weak determinant of consumers' tipping behavior.

Server Attractiveness. Tipping, like other forms of interpersonal behavior, appears to be affected by the server's physical appearance. Several studies have found that restaurant servers receive slightly larger tips the more attractive they are (Hornik 1992; Lynn 1992; May 1978).

Customer Sex. Consistent with stereotypes about women tippers (McCarty et al. 1990), several studies have found that men leave larger tips than do women (Crusco and Wetzel 1984; Karen 1962; Lynn and Latane 1984; Pearl 1985; Pearl and Sudman 1983; Pearl and Vidman 1988; Stillman and Hensley 1980; Tidd and Lockard 1978). The explanation for this sex difference is not clear, but researchers have speculated that it may be due to differences between men's and women's incomes, familiarities with tipping norms, and/or desires to impress waitresses.

Dining-Party Size. Dining-party size is a commonly examined, but inconsistent, predictor of restaurant tipping. Several studies have found an inverse relationship between dining-party size and bill-adjusted tip amounts (Freeman et al. 1975; Lynn 1992; May 1978; Pearl 1985; Pearl and Sudman 1983; Pearl and Vidman 1988). However, a number of other studies have failed to replicate this finding (Crusco and Wetzel 1984; Lynn 1988; Lynn and Grassman 1992; Lynn and Lynn 1992; Lynn and Mynier 1993). The inverse relationship observed in some studies has been attributed to (1) a diffusion of the shared responsibility that each group member has for the waiter or waitress, (2) an equitable adjustment for the smaller per-person service effort required to wait on larger tables, (3) a cost-reducing adjustment for the larger bill sizes acquired by larger tables, and (4) a statistical artifact associated with the use of a ratio variable like percent tip (see Lynn and Bond 1992).

Patronage Frequency. Several studies have found that regular patrons leave larger bill-adjusted tips than do new or infrequent patrons (Bodvarsson and Gibson 1991; Lynn and Grassman 1990; Lynn and Lynn 1992).
This relationship remains significant even after controlling for customers' ratings of the food and service, so regular customers do not tip more merely because they perceive the food and service more positively than do nonregular customers. One possibility is that regular customers tip more than nonregular customers because familiarity and expected future interaction increase the value to consumers of the server's social approval (Lynn and Grassman 1990).

Payment Method. The method restaurant customers use to pay their bills appears to affect their tipping decisions. Several studies have found that charge customers leave larger tips than do cash customers.(Feinberg 1986; Garrity and Degelman 1990; Lynn and Latane 1984; Lynn and Mynier 1993; May 1978; Pearl 1985; Pearl and Sudman 1983; Pearl and Vidman 1988). This relationship may be due to the facilitating effects of credit card stimuli on spending and to the reduced psychological impact of costs that have been postponed via the use of credit cards.

Miscellaneous. The preceding paragraphs summarize some of the more commonly examined relationships in the tipping literature. Other variables positively related to tipping in at least one study include (1) the dining-party's consumption of alcohol (Lynn 1988), (2) the amount of sunshine on the day the tip was left (Cunningham 1979), (3) the number of trips the server made to the table (May 1978), (4) the number of courses ordered (Lynn and Grassman 1992), (5) the tipper's socioeconomic status (Pearl 1985), and (6) the size of the metropolitan area (Pearl 1985).

Deficiencies in the Tipping Literature. Despite the multidisciplinary theory and research on tipping briefly reviewed above, there is much we do not know about this consumer behavior. The existing literature on tipping has several deficiencies: (1) there are few tests of the motives hypothesized to underlie tipping, (2) there are few studies of tipping in nonrestaurant settings, (3) there are few studies of tipping outside the United States, and (4) there is little theory, and no research, on the predictors of tipping customs themselves. All of these issues deserve more attention from consumer researchers. However, research on tipping customs (or norms) is particularly deserving of research attention because both casual observation and existing research suggest that tipping is largely norm-driven behavior.

\section{RESEARCH PROBLEM}

Tipping customs and norms vary from country to country. One interesting dimension on which tipping customs vary across countries is in the number of service professions tipped. ${ }^{1}$ In some countries (such as Argen-

\footnotetext{
${ }^{1}$ Countries also differ in the use of automatic service charges (instead of, or in addition to, voluntary tips) and in the customary level (or monetary amount) of tips. These cross-country differences are distinct from cross-country differences in the prevalence of tipping and are likely to have different predictors. Therefore, we have left analyses of these other cross-country differences to future research.
} 
tina, Greece, and the United States) it is customary to tip a large number of service workers while in others (such as New Zealand, Japan, and Sweden) it is customary to tip only a very few service workers (Star 1988). The origins and predictors of these cross-country differences in the prevalence of tipping are poorly understood. Hemenway (1984), May (1978), and Shamir (1984) note that tipping was outlawed in Communist countries, where its status implications were politically unacceptable. Shamir (1984) also points out that tipping is less prevalent in socialist countries. However, that is the extent of the attention this issue has received to date. In the sections below, we provide a more general explanation for cross-country differences in the prevalence of tipping, and we report an empirical test of this explanation.

\section{Theory and Hypotheses}

Much of human behavior is purposive. Individually and collectively, people act in order to obtain desired outcomes or to avoid unwanted ones. Applying this basic principle to cross-country differences in tipping suggests the simple, straightforward, and testable theory that cross-country differences in the prevalence of tipping reflect differences in the value placed on tipping's consequences.

Tipping has numerous consequences. In addition to improving the quality of services, tipping (1) increases the status and power differences between customers and servers, (2) increases uncertainty for both customers and servers, (3) decreases service workers' identification with and commitment to their service organizations, and (4) decreases the social nature of customer-server interactions. In the paragraphs that follow, each of these consequences is described more fully and is used to generate a hypothesis about cross-country differences in the prevalence of tipping.

Tipping Increases Power Differences. Service workers who receive tips generally occupy menial, lowstatus jobs such as that of bartender, cab driver, porter, or waiter (Hemenway 1984). The practice of tipping reinforces and makes salient the inferior status of these workers. The fact that customers may decide how much to tip after services have already been rendered gives the customer power over service workers and communicates distrust in the servers' work ethic (Hemenway 1984). These status and power implications of tipping suggest the following:

H1: Tipping will be less prevalent in those countries where residents have a low tolerance for status and power differences among people.

Tipping Increases Uncertainty. Tipping increases uncertainty for both service workers and their customers. Tips represent a large portion of many service workers' incomes (Schmidt 1985). However, tip income is often variable and is never guaranteed. As Butler and
Skipper (1980) write, "The dictates of custom cannot provide the security of the contract. With no contract to specify tips, one's wages are uncertain" (p. 490). Thus, tipping increases financial uncertainty for service workers. Tipping also increases customer uncertainty. The norms governing tipping are many and varied (Star 1988), so customers are often uncertain about how much to tip or even whether they should tip at all (Mills and Riehle 1987). These considerations suggest the following:

H2: Tipping will be less prevalent in those countries where residents have a low tolerance for uncertainty.

Tipping Weakens Organizational Commitment. One of the less obvious consequences of tipping is that it weakens service workers' ties to the organizations that employ them. Service employees often experience role conflict stemming from the competing demands of their customers and their supervisors (Shamir 1980). To the extent that service workers are dependent on customers for tips, they are likely to assign greater weight to customers' demands than to demands from their supervisors. Furthermore, research suggests that tipping increases the role conflicts experienced by service workers and decreases their job satisfaction (Shamir 1983). Together, these effects of tipping imply a reduced identification with and commitment to the service organization. In turn, this implication suggests the following:

H3: Tipping will be less prevalent in those countries where residents value strong, communal ties to the organizations for which they work.

Tipping Weakens Social Relationships. The final consequence of tipping to be discussed in this article is that it weakens the social relationships between customers and servers. Money is a generalized store of value that is used as a medium of economic exchange (Furnham and Lewis 1986). It is generally considered inappropriate to give money as a gift (Hussein 1984; Webley, Lea, and Portalska 1983) or as a form of reciprocation in close social relationships (Foa 1971). Thus, monetary tips weaken the social relationships between customers and service workers and reduce their interactions to economic exchanges (Shamir 1984). This transformation of customer-server interactions from social to economic exchanges suggests that:

H4: Tipping will be less prevalent in those countries where residents place a high value on social as compared with economic relationships.

\section{METHOD}

In order to test the preceding hypotheses, it is necessary to measure cross-country differences in (1) the prevalence of tipping, (2) the tolerance of power and status differences between people, (3) the tolerance of 
uncertainty, (4) the value placed on communal ties to employing organizations, and (5) the value placed on social as opposed to economic relationships between people. These measures were obtained from secondary sources as described below.

\section{Cross-Country Differences in the Prevalence of Tipping}

Information about cross-country differences in tipping were obtained from The International Guide to Tipping by Nancy Star (1988). This book describes tipping practices for each of 38 different service professions in 34 different countries, making it the most comprehensive guide available. The information in this book was obtained primarily from questionnaires sent to hotels, national railroads, resorts, restaurants, tour groups, and so on in each of the 34 countries covered (N. Star, personal communication).

As already mentioned, Star's (1988) book contained tipping information about 38 service professions in 34 countries. However, only information about 33 service professions in 30 countries was used in this study. ${ }^{2}$ Five service professions were excluded from analysis because those services are not provided in all of the countries studied, and four countries were excluded because measures of the predictor variables (described below) could not be obtained. The information retained for analysis was used to calculate a measure of the prevalence of tipping by coding each service profession in each country as "tipped" or "not tipped" and then adding up the number of tipped professions in each country. The criterion for being a tipped profession was liberal. If the book recommended any monetary tip, regardless of how small the tip or infrequent the circumstances, then that occupation was coded as tipped for that country. ${ }^{3}$ The only exceptions were rare instances in which the book explicitly indicated that natives do not tip but that tourists are expected to. In these cases, the occupation was coded as "nontipped" for that country. Each of the 990 coding decisions was independently made by two judges who agreed on all but one decision. The sole disagreement between these judges was readily resolved upon discussion.

\footnotetext{
${ }^{2}$ The 33 services and professions coded in this study were facial beauticians, fishing boat crews, gas station attendants, golf caddies, tour guides, hair stylists, horseback riding wranglers, hotel bar/tea service personnel, bellmen, chambermaids, concierges, doormen, parking valets, hotel room service personnel, hotel switchboard operators, hotel transportation pickup service drivers, hotel laundry valets, sports instructors, limo drivers, locker room attendants, manicurists, masseuses/masseurs, pool attendants, plane/train porters, captains/head waiters, chefs, maître d's, restaurant musicians, waiters/ waitresses, washroom attendants, bootblacks, taxi drivers, and ushers.

${ }^{3}$ Under this coding scheme, the rounding up of bill amounts was counted as tipping because it represents a voluntary payment of money to service providers. However, this custom of rounding up is rare and involved only a few of our 33 service professions.
}

\section{Cross-Country Differences in Values}

Information about cross-country differences in tipping-related values was obtained from Hofstede (1983). Hofstede obtained responses to 116,000 questionnaires on work-related values from the employees in 50 different countries of a large, multinational industrial corporation and its subsidiaries. This sample is not representative of the various countries' populations. The employees studied were from their countries' middle class rather than from their upper or lower classes. However, we were not interested in countries' absolute scores, but in differences between countries' scores. Hofstede's sample is good for this purpose because the respondents from different countries were well matched on variables such as corporate culture, occupation, education, sex, and age; their only systematic differences were in nationality. Moreover, the validity of these data is attested by the fact that they are significantly related to a variety of other theoretically relevant, country-level data (see Hofstede [1980a] for a review).

Hofstede (1980a, 1983) identified four major dimensions underlying cross-country differences in his data and labeled these dimensions power distance, uncertainty avoidance, individualism versus collectivism, and masculinity versus femininity. $\mathrm{He}$ also developed and published index scores of the 50 countries on these four dimensions. These index scores were used as the predictor variables in this study as described below.

Power Distance. The power distance index measures "the extent to which a society accepts the fact that power in institutions and organizations is distributed unequally" (Hofstede 1980b, p. 45). Among other things, a high score on this index reflects an acceptance of hierarchical power structures, a perception of differences between superior and subordinate, and a belief that power holders are entitled to privileges. A low score reflects the opposite attitude toward power. This index is used to operationalize the predictor variable in $\mathrm{Hy}-$ pothesis 1 . In operational terms, this hypothesis theorizes a positive relationship between the number of tipped professions in a country and that country's power distance index score.

Uncertainty Avoidance. The uncertainty avoidance index measures "the extent to which a society feels threatened by uncertain and ambiguous situations and tries to avoid these situations" (Hofstede 1980b, p. 45). A high score on this index is associated with a high level of anxiety and stress and a concern with security and rule following. A low score is associated with a low level of anxiety and stress, a tolerance of deviance and dissent, and a willingness to take risks. This index is used to operationalize the predictor variable in Hypothesis 2 . In operational terms, this hypothesis theorizes a negative relationship between the number of tipped professions in a country and that country's uncertainty avoidance index score. 
Individualism. The individualism index measures "non-dependence on the organization" for which a person works (Hofstede 1983, p. 54). High scores on this index reflect an "I" mentality, an emotional independence of individuals from organizations, and an emphasis on individual initiative and achievement. Low scores reflects a "we" mentality, an emotional dependence of individuals on organizations, and an emphasis on belonging and loyalty. This index is used to operationalize the predictor variable in Hypothesis 3. In operational terms, this hypothesis theorizes a positive relationship between the number of tipped professions in a country and the country's individualism index score.

Masculinity. The masculinity index measures "the extent to which the dominant values in society are 'masculine'-that is, assertiveness, the acquisition of money and things, and not caring for others, the quality of life, or people" (Hofstede 1980b, p. 46). High scores on this index are associated with clearly differentiated sex roles, male dominance, and an emphasis on achievement, independence, and money. Low scores are associated with fluid sex roles, equality between the sexes, and an emphasis on service, interdependence, and people. This index is used to operationalize the predictor variable in Hypothesis 4. In operational terms, this hypothesis theorizes a positive relationship between the number of tipped professions in a country and the country's masculinity index score.

Interdependence of Hypotheses and Operationalizations. The fact that Hofstede's (1980a, 1983) four value dimensions mapped so well onto our four hypotheses is obviously not just a coincidence. We began with Hofstede's value dimensions and looked for reasonable hypotheses about their relationships to the prevalence of tipping. However, our search for hypotheses was not difficult; the previous tipping literature identified four consequences of tipping that were clearly relevant to Hofstede's four value dimensions. The ready fit between the previously identified consequences of tipping and Hofstede's value dimensions is probably due to the fact that Hofstede's questionnaire concerned work-related values. Since tipping is a form of work compensation, it makes sense that its consequences would map onto the major dimensions underlying work-related values.

\section{RESULTS}

\section{Power Distance Index and Tipping}

The relationship between the countries' power distance index scores and number of tipped professions is graphed in Figure 1. Across all 30 countries, this index correlated at $.40(p<.03)$ with the prevalence of tipping. However, Japan appeared to be an outlier as its studentized residual was 2.59 SDs from the mean, so an additional analysis was performed omitting Japan from
FIGURE 1

TIPPING AND POWER DISTANCE

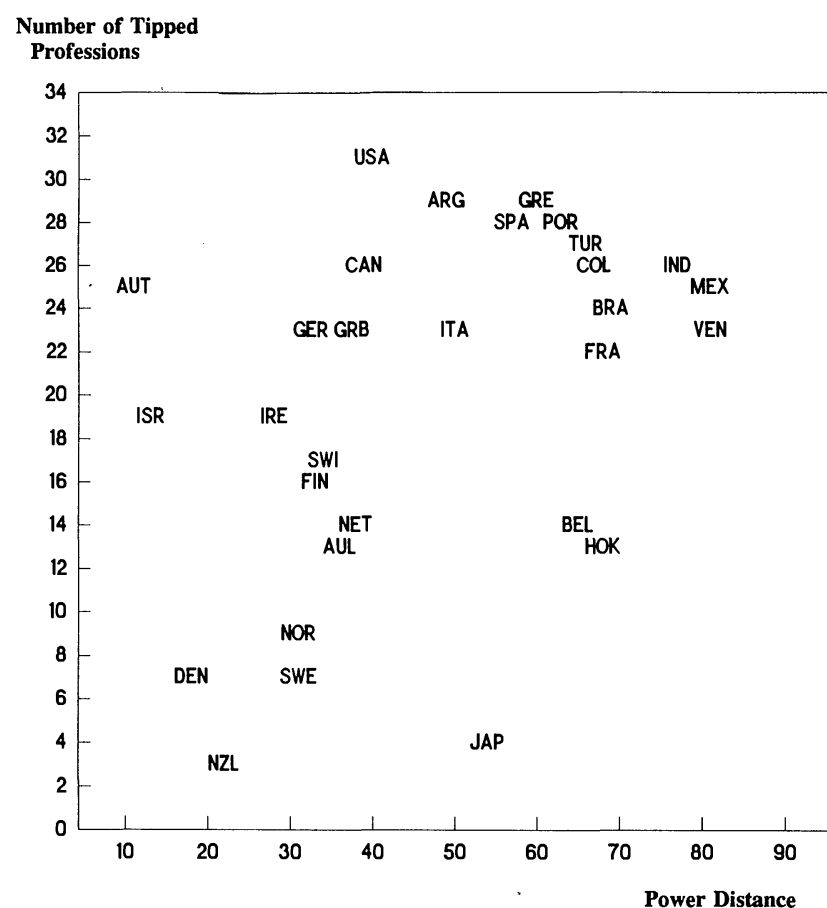

Note.-AUL, Australia; AUT, Austria; ARG, Argentina; BEL, Belgium; BRA, Brazil; CAN, Canada; COL, Colombia; DEN, Denmark; FRA, France; FIN, Finland; GER, Germany; GRB, Great Britain; GRE, Greece; HOK, Hong Kong; IND, India IRE, Ireland; ISR, Israel; ITA, Italy; JAP, Japan; MEX, Mexico; NET, Netherlands: NOR, Norway; NZL, New Zealand; POR, Portugal; SPA, Spain; SWE, Sweden; SWI, Switzerland; TUR, Turkey; USA, United States; VEN, Venezuela.

the data set. In this analysis, the power distance index correlated at $.46(p<.02)$ with the prevalence of tipping. Thus, Hypothesis 1 was supported. Tipping does appear to be more prevalent in countries with a high tolerance of status and power differences between people than in countries whose tolerance of such differences is lower.

\section{Uncertainty Avoidance Index and Tipping}

The relationship between the countries' uncertainty avoidance index scores and number of tipped professions is graphed in Figure 2. Across all 30 countries, this index correlated at $.42(p<.02)$ with the prevalence of tipping. However, Japan was a significant outlier in this analysis too; its studentized residual was 3.36 SDs from the mean. When this outlier was omitted from the analysis, the uncertainty avoidance index correlated at $.55(p<.002)$ with the number of tipped professions. Contrary to expectations, tipping was more (not less) prevalent the less tolerant countries were of uncertainty. Thus, Hypothesis 2 was not supported. One potential explanation for this unexpected result is that tipping reduces experienced uncertainty by giving consumers a sense of control over service delivery. 
FIGURE 2

TIPPING AND UNCERTAINTY AVOIDANCE

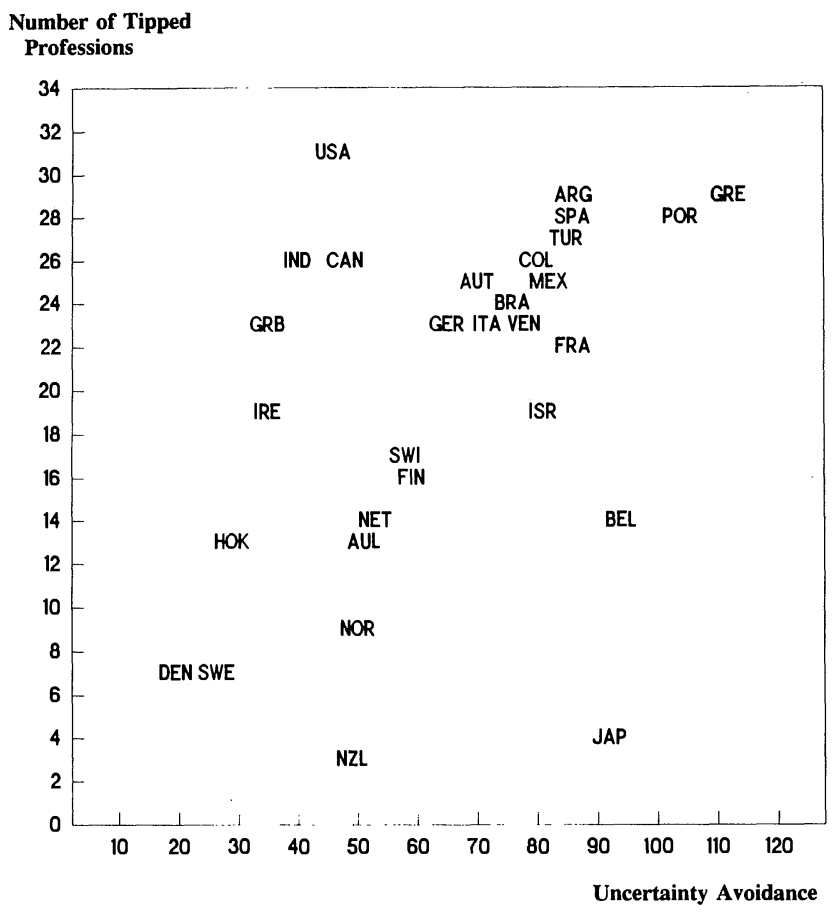

NOTE.-AUL, Australia; AUT, Austria; ARG, Argentina; BEL, Belgium; BRA Brazil; CAN, Canada; COL, Colombia; DEN, Denmark; FRA, France; FIN, Finland; GER, Germany; GRB, Great Britain; GRE, Greece; HOK, Hong Kong; IND, India; IRE, Ireland; ISR, Israel; ITA, Italy; JAP, Japan; MEX, Mexico; NET, Netherlands; NOR, Norway; NZL, New Zealand; POR, Portugal; SPA, Spain; SWE, Sweden; SWI, Switzerland; TUR, Turkey; USA, United States; VEN, Venezuela.

\section{Individualism Index and Tipping}

The relationship between the countries' individualism index scores and number of tipped professions is graphed in Figure 3 . Across all 30 countries, this index correlated at $-.33(p<.08)$ with the number of tipped professions. Again, Japan was an outlier with a studentized residual 2.56 SDs from the mean. Omitting Japan from the analysis resulted in a correlation of $-.39(p$ $<.04$ ) between the individualism index and the number of tipped professions. Contrary to expectations, tipping was more (not less) prevalent in communalistic countries than in individualistic ones. Thus, Hypothesis 3 also failed to receive support. This unexpected result is difficult to explain. However, it may be attributable to the confounding of the individualism index with the power distance index and the uncertainty avoidance index (see Table 1).

\section{Masculinity Index and Tipping}

The relationship between the countries' masculinity index scores and number of tipped professions is graphed in Figure 4. Across all 30 countries, this index
FIGURE 3

TIPPING AND INDIVIDUALISM

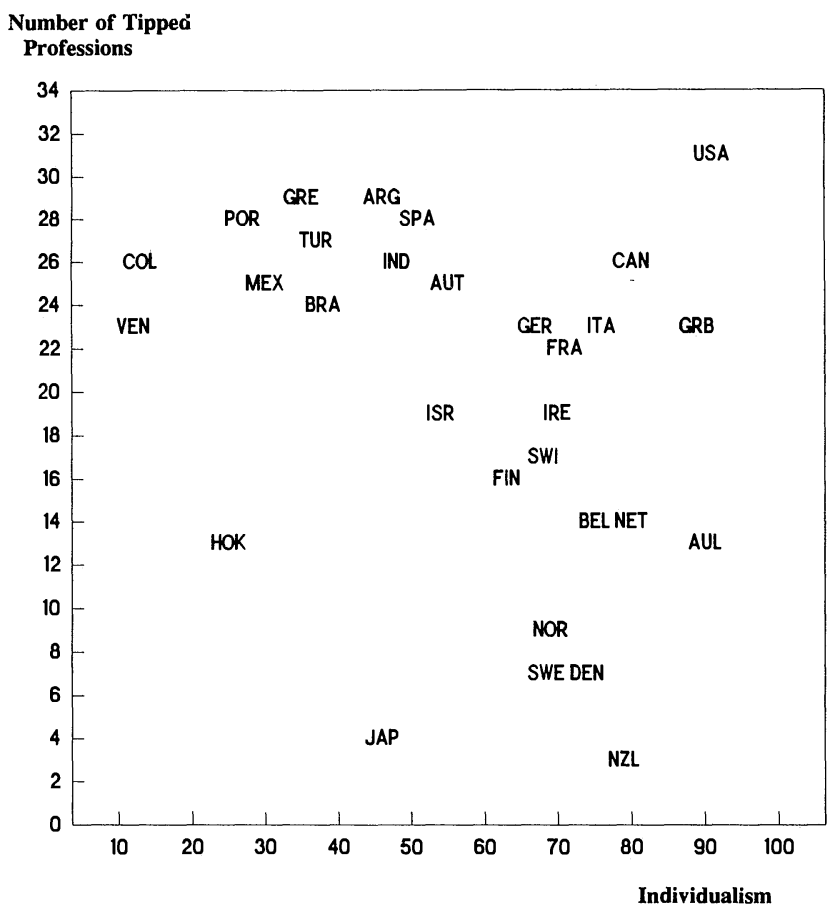

NOTE.-AUL, Australia; AUT, Austria; ARG, Argentina; BEL, Belgium; BRA Brazil; CAN, Canada; COL, Colombia; DEN, Denmark; FRA, France; FIN, Finland; GER, Germany; GRB, Great Britain; GRE, Greece; HOK, Hong Kong; IND, India; IRE, Ireland; ISR, Israel; ITA, Italy; JAP, Japan; MEX, Mexico; NET, Netherlands; NOR, Norway; NZL, New Zealand; POR, Portugal; SPA, Spain; SWE, Sweden; SWI, Switzerland; TUR, Turkey; USA, United States; VEN, Venezuela.

correlated at $.26(p<.17)$ with the prevalence of tipping. However, Japan was an outlier once again with a studentized residual that was 3.60 SDs from the mean. When Japan was omitted from the analysis, the masculinity index correlated at $.47(p<.02)$ with the number of tipped professions. Thus, Hypothesis 4 was supported. Tipping does appear to be less prevalent in countries with feminine values that emphasize social relationships compared with countries with masculine values that emphasize achievement and economic relationships.

\section{Multivariate Analysis}

The 30 countries' scores on the power distance index, the uncertainty avoidance index, the individualism index, and the masculinity index were moderately correlated with one another (see Table 1). This multicollinearity raises questions about whether or not the scores explain unique variance in the number of tipped professions. To answer this question, a simultaneous multiple regression was performed predicting the number of tipped professions from all four value indices. Japan was omitted as an outlier in this analysis because 
TABLE 1

INTERCORRELATIONS AMONG COUNTRIES' VALUE INDICES AND NUMBER OF TIPPED PROFESSIONS

\begin{tabular}{|c|c|c|c|c|c|}
\hline & $\begin{array}{l}\text { Power distance } \\
\text { index } \\
\text { (PDI) }\end{array}$ & $\begin{array}{c}\text { Uncertainty } \\
\text { avoidance index } \\
\text { (UAl) }\end{array}$ & $\begin{array}{l}\text { Individualism } \\
\text { index } \\
\text { (IDV) }\end{array}$ & $\begin{array}{l}\text { Masculinity } \\
\text { index } \\
\text { (MAS) }\end{array}$ & $\begin{array}{l}\text { Number of tipped } \\
\text { professions } \\
\text { (TIP) }\end{array}$ \\
\hline PDI & & $.45^{\star}$ & $-.64^{\star}$ & .21 & $.40^{*}$ \\
\hline UAI & $.45^{\star}$ & & $-.49^{\star}$ & .26 & $.42^{\star}$ \\
\hline IDV & $-.64^{\star}$ & $-.49^{\star}$ & & -.19 & -.33 \\
\hline MAS & .20 & .20 & -.17 & & .26 \\
\hline TIP & $.46^{\star}$ & $.55^{\star}$ & $-.39^{\star}$ & $.47^{\star}$ & $\ldots$ \\
\hline
\end{tabular}

NOTE.-Correlations above the diagonal include Japan; those below the diagonal do not.

${ }^{\star} p<.05$.

its studentized residual was 4.77 SDs from the mean. Given the small sample size and resulting lack of power, it was the size of the partial correlations rather than their statistical significance that was of interest. This analysis produced nonzero partial correlation coefficients for the power distance index (partial $r=.21$, onetailed $p<.15$ ), the uncertainty avoidance index (partial $r=.41$, one-tailed $p<.02$ ), and the masculinity index (partial $r=.43$, one-tailed $p<.02$ ), but not for the individualism index (partial $r=.00, p=.95$ ). Thus, those values whose relationships to the prevalence of tipping were psychologically interpretable (power distance, uncertainty avoidance, and masculinity) did account for modest, but nontrivial, amounts of unique variance in the prevalence of tipping across countries. The one value whose zero-order correlation with the number of tipped professions was not psychologically interpretable (individualism) accounted for no unique variance in the prevalence of tipping.

\section{Analysis of Outliers}

In each of the analyses reported above, Japan was a significant outlier whose residuals were larger than those of any other country. The consistency of this finding suggests that it is not simply a result of measurement or sampling error; some unmodeled factor unique to Japan must be responsible for the low prevalence of tipping in that country. One candidate for this unmodeled factor is the extreme emphasis the Japanese place on repaying debts and obligations. This emphasis is reflected in the Japanese concept of on. In The Chrysanthemum and the Sword, Ruth Benedict (1946, p. 104) wrote the following about on:

People do not like to shoulder casually the debt of gratitude which on implies. They are always talking of "making a person wear an on" and often the nearest translation is "imposing on another"-though in the United States "imposing" means demanding something of another and in Japan the phrase means giving him something or doing him a kindness. Casual favors from relative strangers are the ones most resented, for with neighbors and in oldestablished hierarchal relationships a man knows and has accepted the complications of on. But with mere acquaintances and near equals men chafe. They would prefer to avoid getting entangled in the consequences of $o n$.

Tipping is enmeshed in implications about gratitude, indebtedness, and obligation between service workers and their customers. To tip a service worker is either to express gratitude to the worker and to reciprocate him or her for services received or to obligate the worker for receiving something undeserved. In either case, tipping involves precisely those complications of on between near strangers that the Japanese try to avoid. This may explain why tipping is so rare in Japan despite values on the power distance index, the uncertainty avoidance index, the individualism index, and the masculinity index that are associated with higher levels of tipping prevalence in other countries. ${ }^{4}$

There were other outliers in our analyses-most notably New Zealand and the United States. However, these other countries were not as large and consistent outliers as was Japan. Furthermore, no convincing explanations for their outlying residuals could be found. Therefore, all these other countries were retained in the tests of our hypotheses.

\section{CONCLUSIONS}

\section{Summary}

Tipping is a complex phenomenon that can be studied at multiple levels of analysis-namely, at the level of individual tipping decisions, at the level of tipping norms within countries, and at the level of cross-country differences in tipping customs. Previous research has examined individual tipping decisions but has ignored the macrolevel aspects of tipping. In an attempt to address this deficiency and to broaden the tipping literature, we presented and tested the theory that crosscountry differences in the prevalence of tipping reflect

\footnotetext{
${ }^{4} \mathrm{Japan}$ has also emerged as a unique and anomalous culture in other studies (e.g., Bass et al. 1979; Hofstede 1980a). Thus, Japan's status as an outlier in this study may be due to more general factors than is suggested by our domain-specific explanation.
} 
FIGURE 4

TIPPING AND MASCULINITY

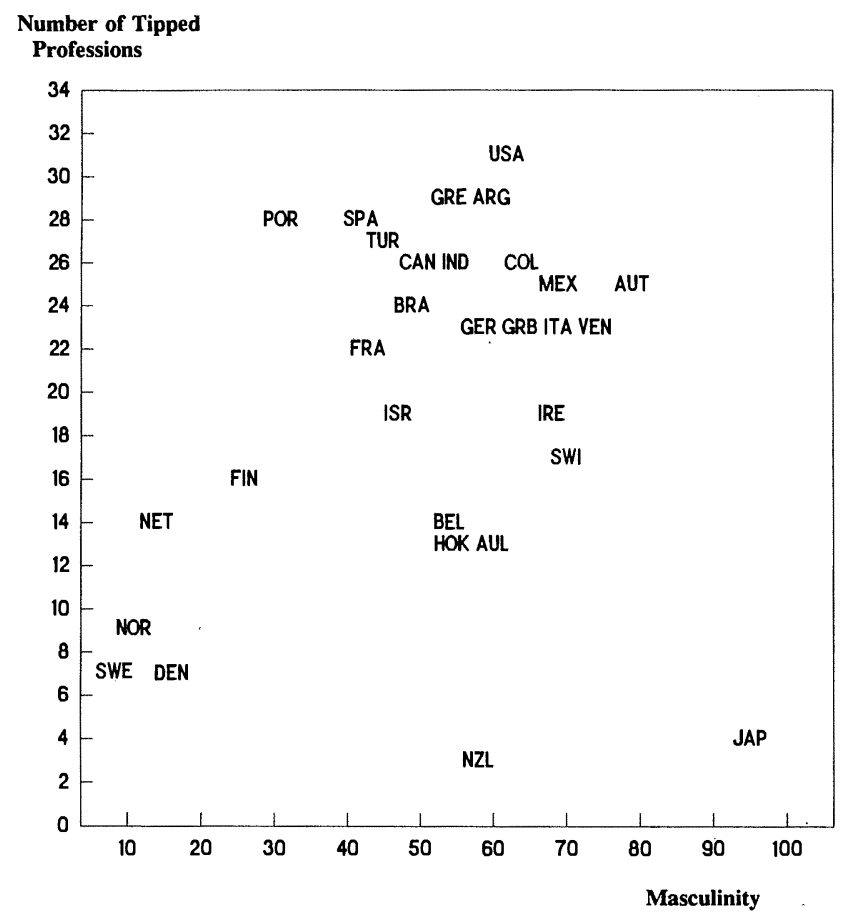

Note.-AUL, Australia; AUT, Austria; ARG, Argentina; BEL, Belgium; BRA, Brazil; CAN, Canada; COL, Colombia; DEN, Denmark; FRA, France; FIN, Finland; GER, Germany; GRB, Great Britain; GRE, Greece; HOK, Hong Kong; IND, India; IRE, Ireland; ISR, Israel; ITA, Italy; JAP, Japan; MEX, Mexico; NET, Netherlands: NOR, Norway; NZL, New Zealand; POR, Portugal; SPA, Spain; SWE, Sweden; SWI, Switzerland; TUR, Turkey; USA, United States; VEN, Venezuela.

differences in the value placed on tipping's consequences. This study found some support for our theory.

As hypothesized, tipping was less prevalent in countries with a low tolerance for status and power differences between people and in countries with feminine values that emphasize social over economic relationships. Unfortunately, other results were less consistent with our theory-based hypotheses. Tipping was more (not less) prevalent in countries with a low tolerance for uncertainty and in communalistic countries that valued close employee ties to work organizations. However, plausible explanations can be generated to reconcile these two unexpected results with the general theory. The first of these results may reflect the fact that uncertainty-aversive consumers value the sense of control over service encounters that tipping provides. The second of these results may reflect the fact that crosscountry differences in individualism and communalism are confounded with differences in the acceptance of uncertainty and of power differences between people. Thus, the two failures to support our hypotheses do not necessarily disconfirm our theory about cross-country differences in the prevalence of tipping, but they do point out deficiencies in our original application of the theory to these value domains.

\section{Independence of Different Levels of Analysis}

Although tipping can be studied at multiple levels of analysis, it is important to note that relationships observed at one level of analysis cannot be directly generalized to another. For example, individual-level data indicated that men leave larger tips than do women, but this finding does not necessarily mean that people in countries with masculine values leave larger tips than do people in countries with feminine values. Similarly, cross-country data indicated that people in countries with high tolerances for power differences tip a greater number of professions than do people in countries with low tolerances for power differences, but this finding does not necessarily mean that individuals with a greater desire for power tip more professions than do individuals with a weaker desire for power. It is precisely this inability to generalize from one level of analysis to another that necessitates the study of tipping at multiple levels of analysis.

\section{Future Research}

Very little research has examined macrolevel aspects of tipping. The present study's focus on cross-country differences in the prevalence of tipping is an exception to this general neglect. However, this study is necessarily limited in scope. In the future, consumer researchers should examine other macrolevel aspects of tipping such as (1) the characteristics that differentiate tipped from nontipped service professions, (2) cross-country differences in the customary level or sizes of tips, ${ }^{5}$ and (3) the relationship between tipping and automatic service charges across countries. (In many countries service charges have replaced tipping while in other countries tips are expected on top of service charges.) We encourage consumer researchers to address these various issues and to make progress toward understanding this fascinating consumer behavior.

\section{[Received August 1992. Revised February 1993.]}

\section{REFERENCES}

Bass, Bernard M., Philip C. Burger, Robert Doktor, and Gerald V. Barrett (1979), Assessment of Managers: An International Comparison, New York: Free Press.

Benedict, Ruth (1946), The Chrysanthemum and the Sword, Boston: Houghton Mifflin.

\footnotetext{
${ }^{5}$ Comparing the customary level of tipping across countries will be problematic because the absence of standard bill sizes, monetary units, and tipping customs (some service providers are tipped a percentage of the bill while others are tipped a specific monetary amount) poses measurement difficulties. However, these difficulties are not insurmountable, and we feel that the topic is sufficiently interesting to justify the effort involved.
} 
Berry, Leonard L. (1980), "Services Marketing Is Different," Business, 30 (May-June), 24-28.

Bodvarsson, Orn B. and William A. Gibson (1988), "Towards an Economic Theory of Tipping: A Transactions Cost View," paper presented at the Western Economic Association Meetings, Los Angeles.

- and William A. Gibson (1991), "Towards an Economic Theory of Tipping: Tipping of Restaurant Staff," paper presented at the Western Economic Association Meetings, Seattle.

Butler, Suellen and James K. Skipper (1980), "Waitressing, Vulnerability and Job Autonomy: The Case of the Risky Tip," Sociology of Work and Occupations, 7 (November), 487-502.

$\rightarrow$ Crespi, Leo P. (1947), "The Implications of Tipping in America," Public Opinion Quarterly, 11 (Fall), 424-435.

Crusco, April H. and Christopher G. Wetzel (1984), "The Midas Touch: The Effects of Interpersonal Touch on Restaurant Tipping," Personality and Social Psychology Bulletin, 10 (December), 512-517.

Cunningham, Michael R. (1979), "Weather, Mood and Helping Behavior: Quasi Experiments with the Sunshine Samaritan," Journal of Personality and Social Psychology, 37 (November), 1947-1956.

$\rightarrow$ Feinberg, Richard A. (1986), "Credit Cards as Spending Facilitating Stimuli: A Conditioning Interpretation," Journal of Consumer Research, 13 (December), 348-356.

$\rightarrow$ Foa, Uriel (1971), "Interpersonal and Economic Resources," Science, 171 (January), 345-352.

Freeman, Stephen, Markus R. Walker, Richard Borden, and Bibb Latané (1975), "Diffusion of Responsibility and Restaurant Tipping: Cheaper by the Bunch," Personality and Social Psychology Bulletin, 1 (Fall), 584-587.

Furnham, Adrian and Alan Lewis (1986), The Economic Mind, New York: St. Martin's.

Garrity, Kimberly and Douglas Degelman (1990), "Effect of Server Introduction on Restaurant Tipping," Journal of Applied Social Psychology, 20 (February), 168-172.

Hemenway, David (1984), Prices and Choices: Microeconomic Vignettes, Cambridge, MA: Ballinger.

Hofstede, Geert (1980a), Culture's Consequences: International Differences in Work-related Values, Beverly Hills, CA: Sage.

(1980b), "Motivation, Leadership and Organization: Do American Theories Apply Abroad?" Organizational Dynamics, 9 (Summer), 42-63.

- (1983), "National Cultures in Four Dimensions: A Research-based Theory of Cultural Differences among Nations," International Studies of Management and Organization, 8 (Spring/Summer), 46-74.

Holloway, J. Christopher (1985), "Between Gratitude and Gratuity: Commentary on Shamir," Annals of Tourism Research, 12, 239-242.

Hornik, Jacob (1992), "Tactile Stimulation and Consumer Response," Journal of Consumer Research, 19 (December), 449-458.

Hussein, G. (1984), "Is Money an Unacceptable Gift in Cyprus?" unpublished manuscript cited in The Individual in the Economy, ed. Stephen E. G. Lea et al., Cambridge: Cambridge University Press, 1987, p. 333.

$\rightarrow$ Jacob, Nancy and Alfred Page (1980), "Production, Information Costs, and Economic Organization: The Buyer
Monitoring Case," American Economic Review, 70 (June), 476-478.

Karen, Robert (1962), "Some Factors Affecting Tipping," Sociology and Social Research, 47 (October), 68-74.

Ledger, Jack (1974), "Tipping: The Customer's Point of View," Canadian Hotel and Restaurant, 52 (May), 2629.

Lynn, Michael (1988), "The Effects of Alcohol Consumption on Restaurant Tipping," Personality and Social Psychology Bulletin, 14 (March), 87-91.

(1992), "Service Gratuities: A Reflection of Consumer's Evaluations of the Service Encounter?" unpublished manuscript, Marketing Department, University of Houston, Houston, TX 77204.

- and Charles F. Bond (1992), "Conceptual Meaning and Spuriousness in Ratio Correlations: The Case of Restaurant Tipping," Journal of Applied Social Psychology, 22 (February), 327-341.

and Andrea Grassman (1990), "Restaurant Tipping: An Examination of Three 'Rational Explanations'," Journal of Economic Psychology, 11 (June), 169-181.

and Andrea Grassman (1992), "The Relationship Between Service Quality and Gratuity Size: A Conceptual Replication," unpublished manuscript, Marketing Department, University of Missouri-Columbia, Columbia, MO 65211 .

_ and Bibb Latané (1984), "The Psychology of Restaurant Tipping," Journal of Applied Social Psychology, 14 (November/December), 551-563.

and Ann Lynn (1992), "Frequency of Patronage and Compliance with the Fifteen Percent Tipping Norm," unpublished manuscript, Marketing Department, University of Houston, Houston, TX 77204.

_ and Kirby Mynier (1993), "Effect of Server Posture on Restaurant Tipping," Journal of Applied Social Psychology, 23 (8), 678-685.

May, Joanne M. (1978), "Tip or Treat: A Study of Factors Affecting Tipping Behavior," unpublished master's thesis, Loyola University, Chicago, IL 60626.

McCarty, John A., L. J. Shrum, Tracey E. Conrad-Katz, and Zacho Kane (1990), "Tipping as Consumer Behavior: A Qualitative Investigation," in Advances in Consumer Research, Vol. 17, ed. Marvin E. Goldberg et al., Provo, UT: Association for Consumer Research, 723-728.

Mills, Susan and Hudson Riehle (1987), "What Customers Think about Tips vs. Service Charges," Restaurants USA, 7 (October), 20-22.

Pearl, Robert B. (1985), "Tipping Practices of American Households: 1984," final report to the Internal Revenue Service under contract TIR 82-21, Survey Research Laboratory, University of Illinois, Champaign, IL 61820.

- and Seymour Sudman (1983), "A Survey Approach to Estimating the Tipping Practices of Consumers," final report to the IRS under contract TIR 82-21, Survey Research Laboratory, University of Illinois, Champaign, IL 61820.

- and John Vidman (1988), "Tipping Practices of American Households in Restaurant and Other Eating Places: 1985-1986," summary report to the IRS under contract TIR 86-279, Survey Research Laboratory, University of Illinois, Champaign, IL 61820.

Schein, John E., Edwin F. Jablonski, and Barbara R. Wohlfahrt (1984), The Art of Tipping: Customs and Controversies. Wausau, WI: Tippers International. 
Schmidt, Donald G. (1985), "Tips: The Mainstay of Many Hotel Workers' Pay,” Monthly Labor Review, 108 (July), $50-51$.

Scott, William R. (1916), The Itching Palm: A Study of the Habit of Tipping in America, Philadelphia: Penn.

Seligman, Clive, Jean E. Finegan, J. Douglas Hazelwood, and Mark Wilkinson. (1985), "Manipulating Attributions for Profit: A Field Test of the Effects of Attributions on Behavior," Social Cognition, 3 (Fall), 313-321.

Shamir, Boas (1980), "Between Service and Servility: Role Conflict in Subordinate Service Roles," Human Relations, 33 (October), 741-756.

(1983), "A Note on Tipping and Employee Perception and Attitudes," Journal of Occupational Psychology, 56 (September), 255-259.

(1984), "Between Gratitude and Gratuity: An Analysis of Tipping," Annals of Tourism Research, 11, 59-78.

Snyder, Melvin L. (1976), "The Inverse Relationship between Restaurant Party Size and Tip Percentage: Diffusion or Equity?" Personality and Social Psychology Bulletin, 2 (Summer), 308.
Star, Nancy (1988), The International Guide to Tipping, New York: Berkeley.

Stephen, Renee and Richard L. Zweigenhaft (1986), "The Effect on Tipping of a Waitress Touching Male and Female Customers," Journal of Social Psychology, 126 (February), 141-142.

Stillman, JeriJane W. and Wayne E. Hensley (1980), "She Wore a Flower in Her Hair: The Effect of Ornamentation on Non-verbal Communication," Journal of Applied Communication Research, 1, 31-39.

Tidd, Kathi L. and Joan S. Lockard (1978), "Monetary Significance of the Affiliative Smile: A Case for Reciprocal Altruism," Bulletin of the Psychonomic Society, 11 (June), 344-346.

Webley, Paul, Stephen E. G. Lea, and R. Portalska (1983), "The Unacceptability of Money as a Gift," Journal of Economic Psychology, 4 (November), 223-238.

$\rightarrow$ Zeithaml, Valarie A., Leonard L. Berry, and A. Parasuraman (1988), "Communication and Control Process in the Delivery of Service Quality," Journal of Marketing, 52 (April), 35-48. 